\title{
Public opinion on coronavirus vaccination 1: A majority of Americans would take the existing Russian vaccine and believe that they ought to be allowed to buy it
}

\author{
Jonathan Kelley [a] \\ Principal Investigator, International Social Science Survey \\ kelley@InternationalSurveyCenter.org \\ MDR Evans [b] \\ Professor of Sociology, University of Nevada \\ MariahEv2@gmail.com \\ Charlotte Corday \\ Senior Researcher, International Survey Center \\ ccorday@InternationalSurveyCenter.org
}

October 2020

[a] Sociologist. Academic survey researcher, heavy duty quant. Cambridge BA, Berkeley PhD. 5 books; $120+$ papers in ASR, AJS, Nature Biotechnology, BJS, APSR, etc. Cited in the academic literature 7000+ times. Previously Senior Fellow and Director of the International Survey Project, Institute of Advanced Studies, The Australian National University and Professorial Fellow, Melbourne Institute of Applied Economic and Social Research, the University of Melbourne. Now Adjunct Professor of Sociology, University of Nevada, Reno. Twitter: @IsssSurvey

[b] MDR (Mariah) Evans. Currently at the University of Nevada, Reno: Professor, Department of Sociology and Nevada Agricultural Experiment Station; Director of Graduate Studies in Sociology; Faculty member, Interdisciplinary PhD Program in Social Psychology. Coordinator, Applied Statistics Program. Education: PhD, University of Chicago; MA, University of IllinoisCampaign; BA, Reed College. Current projects: Inequality Attitudes; Scholarly Culture;

Sociology of Time; Sociology of COVID-19. 


\section{Abstract}

In the US new vaccines are banned until shown to be safe and effective. But the approval process is slow and cautious and no vaccine has yet been approved. The faster but perhaps riskier Russian system produced an approved coronavirus vaccine months more quickly, leaving Americans at risk of dying for months longer than Russians. Our data from two national surveys in September show that a majority of Americans would willingly take the existing Russian vaccine and that a two-to-one majority - rich and poor, young and old, Democrat and Republican alike - believe that they ought to be allowed to do so. We estimate that making the Russian vaccine immediately available would save approximately 40 to 100 American lives each day after the first month and many more subsequently, To put the matter bluntly, current US government policy will kill some 40 to 100 people each day for a considerable period later this year and early next. To put those deaths in context, all American murderers combined kill only 45 people each day - not a record the US government should wish to emulate. There are implications for the 2020 election; Since feelings about the Russian coronavirus vaccine are strongly favorable, and the benefits of allowing it in the US are large, making it available should be attractive politically. The Republican government has the power to adopt that policy and gain the credit. Alternatively, the Democratic opposition has the opportunity to advocate that policy, and claim the credit.

\section{Keywords:}

COVID-19, China, FDA, Public opinion, Russia, Sinovac SARS-CoV-2 Vaccine, Sputnik V, USA, advanced societies, attitudes, challenge trial, coronavirus, globalization, immunity, international, manufacture location, pharma, pharmaceuticals, survey, survey research, vaccine, vaccine acceptability, vaccine hesitancy, vax. 2020 Election, Republicans gain, Democrats gain

\section{Introduction}

With vaccines as yet unavailable in the US, deaths from coronavirus are running somewhere around 700 to 900 per day in the autumn of 2020 according to CDC figures and are expected to go higher in the winter. Vaccines to reduce the toll are in development in America, but are not expected to be approved by the American authorities for several months, perhaps not until sometime next year. And it will likely take some months beyond that beginning for sufficient vaccine to be available, and for there to be sufficient experience with it to persuade everyone who is persuadable to take it. All this leaves Americans at risk for at least two or three months and most likely longer. This risk could be substantially reduced without a miracle or a change in public opinion.

Several other countries have moved faster than the US and have coronavirus vaccines already developed and approved. Russia was among the first, with its "Sputnik V" vaccine. It was described in a peer-reviewed article in The Lancet and approved by the Ministry of Health of the Russian Federation (Minzdrav) in August. 
This paper addresses the possibility that Americans might take advantage of the Russian vaccine to reduce the period they would otherwise be at risk of infection and possible death while awaiting slow-moving American developments.

Data from two national surveys in September (combined $N=2,280$ ) shows that about one American in five is ready, even eager, to use the existing Russian vaccine immediately. Most of the rest say they would be ready to use it after it has been available for a few months. Each of those "vaxers" would not only reduce their own risk of death, but would reduce the risk of infection throughout their social network and transitory contacts, saving the lives of others, as well.

If use of the Russian coronavirus vaccine were permitted in the US, we conservatively estimate that approximately 40 to 100 US lives would be saved each day after the first month of availability. Many more would be saved subsequently, both from the ongoing immunity among the first wave vaccinated, and from subsequent cohorts accepting vaccination. The benefits would continue at least until US vaccines become fully available and fully accepted.

\section{Data}

Data are from the International Social Science Survey (ISSS), Round 21, Cohorts 7 and 8. These are separate internet samples fielded beginning September 13 and September 27 respectively, with almost all completions within a few days of entering the field. The surveys are part of an ongoing ISSS research project on the coronavirus pandemic.

All of the surveys so far are Amazon 'Mechanical Turk' internet-based samples. These can be conducted without risk of contracting coronavirus and, moreover, are swift, convenient, and cost effective. Internet samples of this sort have been widely used during the pandemic (Cornesse and Blom 2020; Graham et al. 2020; McFadden 2020; Liotta, Marazzi, Orlando, \& Palombi 2020).

Extensive research shows that Mechanical Turk samples have proven remarkably accurate for multivariate analyses (Clifford, Jewell and Waggoner 2015; Springer et al. 2016; Weinberg, Freese and McElhattan 2014), specifically for political affiliations and attitudes (Clifford, Jewell and Waggoner 2015) and for science-related issues (Evans and Kelley 2011). We have found that as well, comparing our 2017-2019 internet samples to face-to-face samples in the US and many other countries (from the International Social Survey Programme's highly regarded "Inequality" series).

A disadvantage is that estimation of population means in internet samples and predicted values in regression analyses may need to be adjusted because they typically over represent younger and highly educated people. For the present analysis, such adjustments make no practical difference because the issues dealt with here are not much related to age or education (as we show below). Moreover, estimates from Pew's carefully curated internet sample and our MTurk samples match closely on many COVID-related questions. 


\section{Findings: Widespread acceptance of the Russian coronavirus vaccine}

Willingness to take the Russian vaccine was assessed by a straightforward direct question (preceded by an image of two vials of the vaccine ):
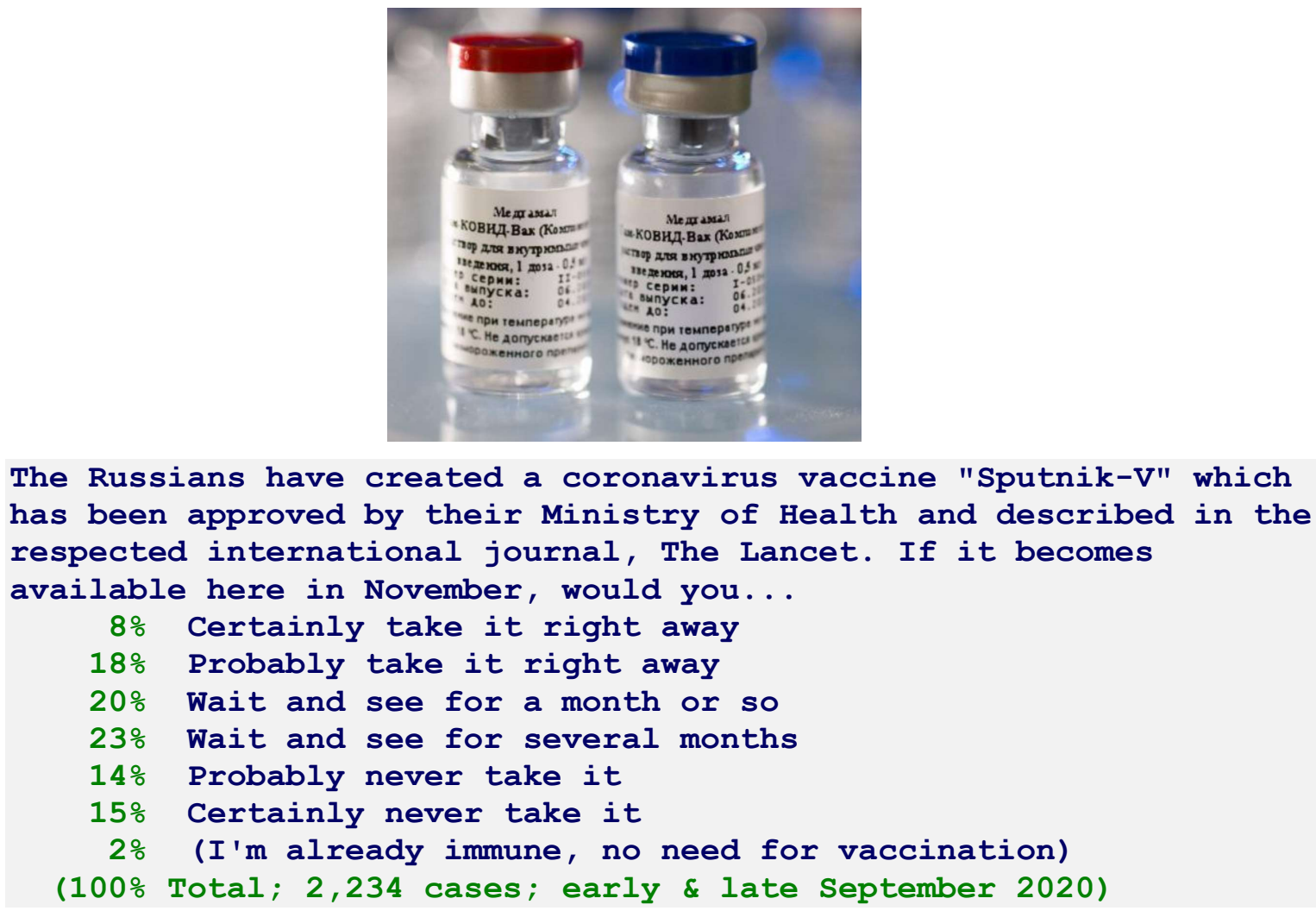

The percentages on the left in green are the percent distribution of the answers (respondents did not see them, nor the other material in green on the bottom row.) Just $2 \%$ believe they are already immune, although actual immunity is probably closer to $10 \%$ (Anad et al., 2020). So, the risk of infection and the issue of vaccination are actually relevant to $90 \%$ of the population and subjectively and behaviorally relevant to $98 \%$.

Americans are surprisingly willing to accept the Russian vaccine. Some 8\% say they would "certainly" take it right away. Another 18\% would "probably" take it right away. More, $20 \%$, would "wait and see for a month or so". Yet more, $23 \%$, would wait and see for several months. The delay is presumably to see whether all goes well for those who took the vaccine right away.

Finally, fewer than a third of all Americans expect that they would "probably" (14\%) or "certainly" (15\%) never take the Russian vaccine.

Thus, there is surprisingly widespread acceptance of the Russian 'Sputnik V' vaccine. Assuming that around two-thirds of the "probably take it right away" group would indeed take the vaccine in the first month or so, that suggests that around $20 \%$ of 
Americans $\left(8 \%+[2 / 3]^{*} 18 \%=20 \%\right)$ would take the Russian vaccine in the first month or so after it becomes available in the US. We will see that that would imply a tremendous savings of American lives.

This $20 \%$ acceptance of the Russian vaccine is only a little lower than a CBS/YouGov poll (CBS 2020) found in the first week of September for a US vaccine (21\% say they would get vaccinated "as soon as possible") with outright rejection (21\% "never") perhaps a little lower than our 15\% "never" and 14\% "probably never" for the Russian vaccine. Pew Research Center results for September are similar (Pew 2020).

We also asked about a hypothetical American vaccine available at the end of the year, our results suggesting $27 \%$ of Americans would take it in the first month, compared to the $20 \%$ we have seen for the Russian vaccine. This means that first month uptake intentions for the Russian vaccine are around $26 \%$ lower than for an American vaccine (viz $20 \%$ for the Russian vaccine, $27 \%$ for the US vaccine, $1-(20 / 27)=26 \%$ lower).

The only other analysis of American intentions to take the Russian vaccine of which we are aware comes to a similar conclusion. A careful conjoint analysis of vaccine uptake intentions based on a late August survey estimated Americans would be $18 \%$ less likely to take a Russian vaccine than to take an otherwise similar American one (Motta 2020, Figure 1).

\section{Who would get vaccinated "right away"?}

Willingness to be vaccinated with the Russian 'Sputnik V' vaccine is widespread throughout American society with no statistically significant difference between young and old, rich and poor, or (more surprisingly in a generally politicized pandemic) between Democrats and Republicans (Table 1).

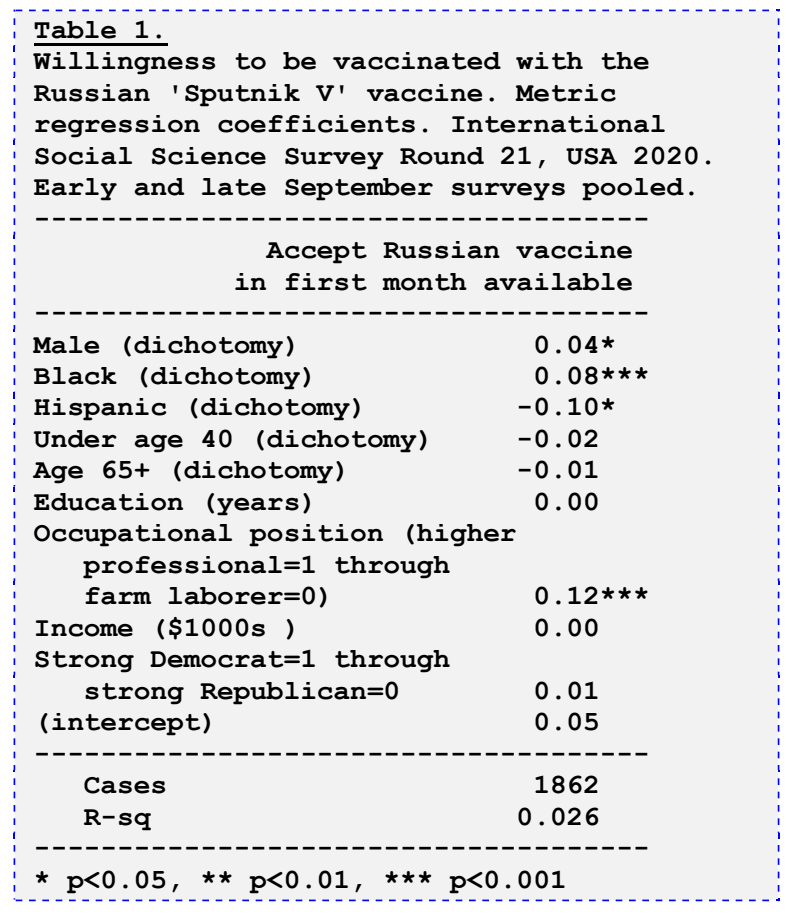


Consistent with past research on vaccination for other diseases (Siddiqui, Salmon and Omer 2013), background and demographic differences are small. Men are fractionally more accepting ( $4 \%$ more likely to be vaccinated; $\mathrm{t}=2.29, \mathrm{p}<.05)$. Blacks are $8 \%$ more likely ( $\mathrm{t}=3.98, \mathrm{p}<.001)$ and Hispanics about $10 \%$ less likely $(\mathrm{t}=-2.13, \mathrm{p}<.05)$. The young are not significantly different than the middle aged; nor (more surprisingly) are the old. Well educated university graduates are not significantly different from high school dropouts.

The one socioeconomic difference that clearly matters is occupation: those at the top of the hierarchy (higher professionals like professors, lawyers, and engineers) are around $12 \%$ more likely to accept vaccination than those at the bottom of the hierarchy (like unskilled laborers and farm workers).

In all, demographic and socioeconomic differences explain only a paltry $2.6 \%$ of the variance. We find the same pattern for potential uptake of future American and British vaccines (results not shown).

This near randomness in the potential uptake of the Russian (and other) vaccines has an important implication for understanding vaccination's impact on the epidemic. It means that those who get vaccinated promptly will be a more or less random sample of the population and so would be just as likely (or unlikely) to get infected as anyone else. And so just as likely or unlikely to die as anyone else.

So, for example, if vaccination reaches $20 \%$ of the population and protects (say) $50 \%$ of those vaccinated from subsequent infection, then it reduces the rate of infection - and presumably also the death rate - by $10 \%($ viz $.20 * .50=.10)$.

This is the basic assumption in our model.

\section{The Russian vaccine's potential reduction in American coronavirus deaths}

\subsection{Estimation}

We model the Russian vaccine's possible effect on America's coronavirus death rates simply and straightforwardly (further details in Appendix 1). There is at present no other vaccine available in the US, nor any likely to be available for some months, so we begin with a vaccine tabula rasa.

Deaths from COVID-19 are currently running around 700 to 900 a day as this is written (in October). Death rates were higher earlier in the epidemic, lower for a while in the summer, and are generally expected to be higher again in the coming winter. We take 700 a day as a plausible ballpark figure to work with. Increasing it by (say) half, or reducing it by half, would change our estimates in proportion.

For simplicity and clarity, we consider only the first month's uptake of the Russian vaccine, drawing on the estimates from our survey, specifically $20 \%$ following through with their expressed intention of taking the vaccine "right away" when it becomes available. We assume this is a random $20 \%$ of the population with respect to the risk of infection and the subsequent risk of death. We assume that a quarter get vaccinated in the first week, another quarter the second week, another in the third week, and the 
rest in the fourth week of availability. The result is shown in Figure 1, which illustrates only the first couple of months. The pattern shown there would, we predict, continue as long as immunity from the vaccine lasts and until alternative vaccines become readily available, perhaps three or four months from the beginning.

Uptake of the Russian vaccine in the second and subsequent months would follow the same pattern, with everything starting a month or two later (but likely ending a month or two sooner as alternative vaccines become available next year). How many would take up the vaccine in the second month is not easy to know, perhaps two-thirds of the $20 \%$ who now say they would "Wait and see for a month or so". So too for the third month for the $23 \%$ who now say they would "Wait and see for several months". A few, perhaps a third, of the $14 \%$ who now say they would "Probably never take it" might relent at some point. All this would protect an additional $33 \%\left(\mathrm{viz}\left[{ }^{2} / 3\right]^{*} 20 \%+\right.$ $[2 / 3]^{*} 23 \%+[1 / 3]^{*} 14 \%=33 \%$ ), bringing the total protected to $53 \%$. This second wave would save more lives, perhaps as many again as saved by the first month's cohort. For simplicity we do not graph these possibilities in Figure 1.

We assume that some people would have a bad reaction to the vaccine, pessimistically taking the worst recent experience as our model, namely the 1976 swine flu vaccine. Approximately 45 million people were vaccinated then, resulting in 53 deaths due to the vaccine (Millera et al. 2015). Scaling that up to the current US population of 300 million, that corresponds to some 350 vaccine-related deaths. This in a coronavirus epidemic which has already killed some 200,000. So even under these pessimistic assumptions, vaccine-caused deaths are small in the big picture, almost negligible indeed orders of magnitude less than coronavirus-caused deaths (Figure 1, in red).

\subsection{Implications}

The results of these rough and ready calculations are shown in Figure 1. If use of the Russian coronavirus vaccine were permitted in the US, our analysis implies that at least 40 to 100 US lives would be saved each day after the first month of availability. The benefits ramp up in the first month, as vaccination proceeds throughout the month.

Many more lives would be saved subsequently, both from the on-going immunity among the first wave vaccinated, and from subsequent cohorts accepting vaccination. The benefits would continue at least until US vaccines become fully available and fully accepted. 
Figure 1.

Estimated American lives saved each day (shown in green) or lost each day (shown in red) if use of the Russian coronavirus vaccine was permitted in the US in the autumn of 2020 before US vaccines are available. Vaccine uptake estimated from two national surveys in September (International Social Science Survey, Round 21, US Cohorts $7 \&$ 8; combined N= $2,280)$. Vaccine risks are worst-case estimates. Vaccine effectiveness (\% of infections prevented) is estimated alternatively as very low $(25 \%)$, low $(50 \%)$, or good $(75 \%)$. Deaths in the absence of vaccination are estimated as 700 per day based on rates observed in the autumn. Estimates shown are for the approximately $20 \%$ of Americans who say they would take up the Russian vaccine "right away". The $30 \%$ or $40 \%$ who would "wait and see" for a month or more are not included; their outcomes would be in similar in pattern but starting a month or more later.

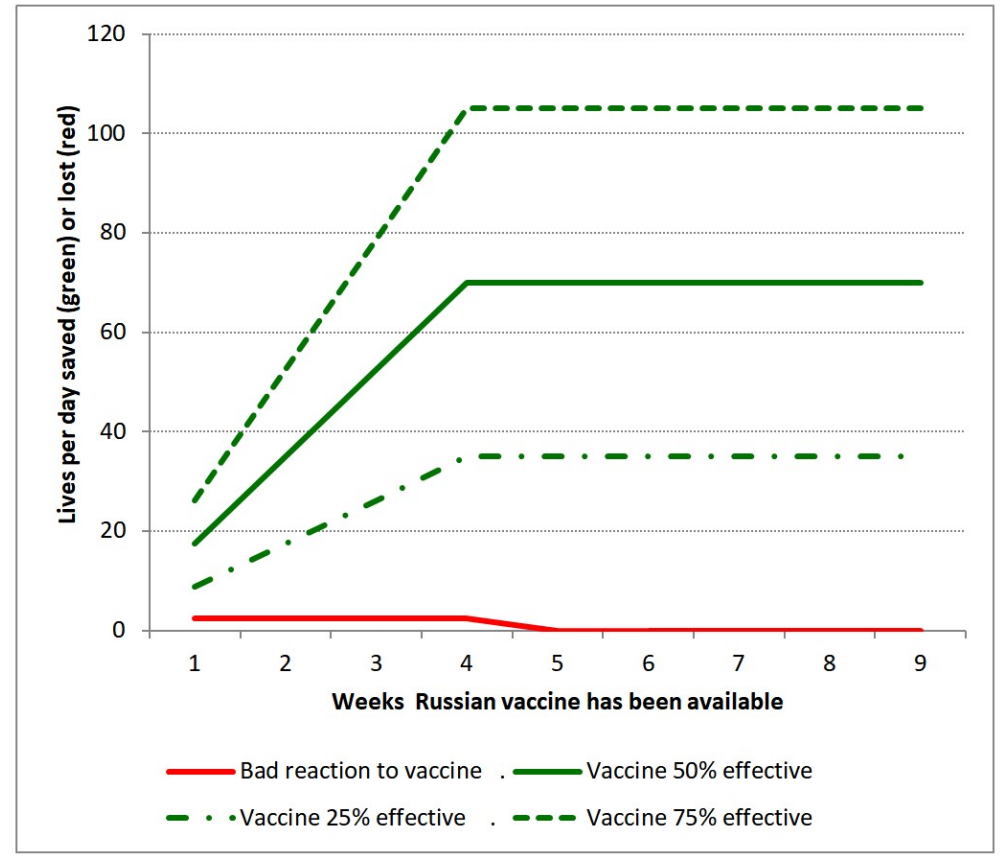

How many lives would be saved depends heavily on how effective the vaccine turns out to be in preventing COVID-19 infection. But even if it is a very poor vaccine, preventing only $25 \%$ of infections (far below what the FDA would consider adequate), it would still save a lot of lives. The reason is that "getting vaxed" hardly ever kills anyone (the red line in Figure 1) so that almost any prevention a vaccine gives is a gain. Saving some lives while waiting for a better alternative to emerge is better than doing nothing, which saves none and costs many lives.

A vaccine that is $50 \%$ effective in preventing infection (the minimum the FDA would consider adequate) would do much better, saving around 70 lives per day after the first few weeks (solid green line in Figure 1). And that protection would continue months into the future, assuming that immunity once established continues for at least some months (as is usually the case for vaccines against other coronaviruses). And all this comes from vaccinating just $20 \%$ of the population; vaccinating more would save more. 
Finally, a vaccine that is $75 \%$ effective (good but not unusually good) would, we estimate, save something like 100 lives per day after it has been deployed for a while (Figure 1, dashed line in green, for weeks 5 onward).

What, then, do the American people think about this?

\section{A two-to-one majority believe Americans should be allowed to buy the Russian vaccine}

The question, asked in our two September surveys:

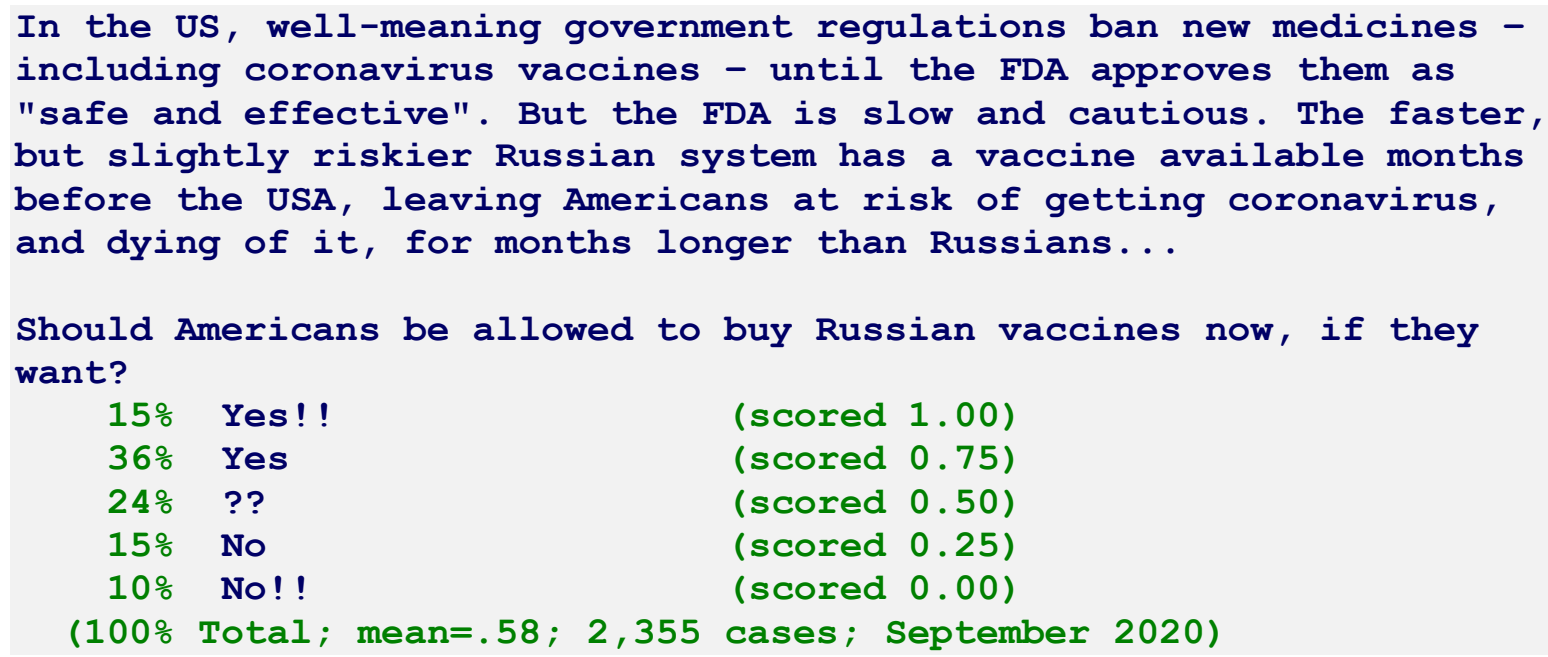

The percentages on the left in green are the precent distribution of the answers. Scoring for the regression is shown on the right, also in green (it approximates probabilities). Respondents did not see any of the material in green.

A majority of Americans believe they should be allowed to buy Russian vaccines if they want, $51 \%$ (viz $15 \%+36 \%)$. Only $25 \%$ are opposed $(15 \%+10 \%)$, so that is a two-toone majority in favor.

Quite a few are, however, undecided, $24 \%$. If the question were put to a referendum where the undecided had to make up their mind one way or another, or abstain altogether, the likely result would be $58 \%$ in favor and $42 \%$ opposed.

Background and demographic differences of opinion are small (Table 2). Men are a trifle more in favor of being allowed to buy the Russian vaccine $(3 \%$ more $t=2.36$, $\mathrm{p}<.05)$. Blacks are $9 \%$ more favorable $(\mathrm{t}=5.22, \mathrm{p}<.001)$ and Hispanics are not $(\mathrm{t}=-0.26$, n.s.). Neither young nor old are significantly different than the middle aged. Nor are well educated university graduates significantly different from those with less education. Income is irrelevant. 


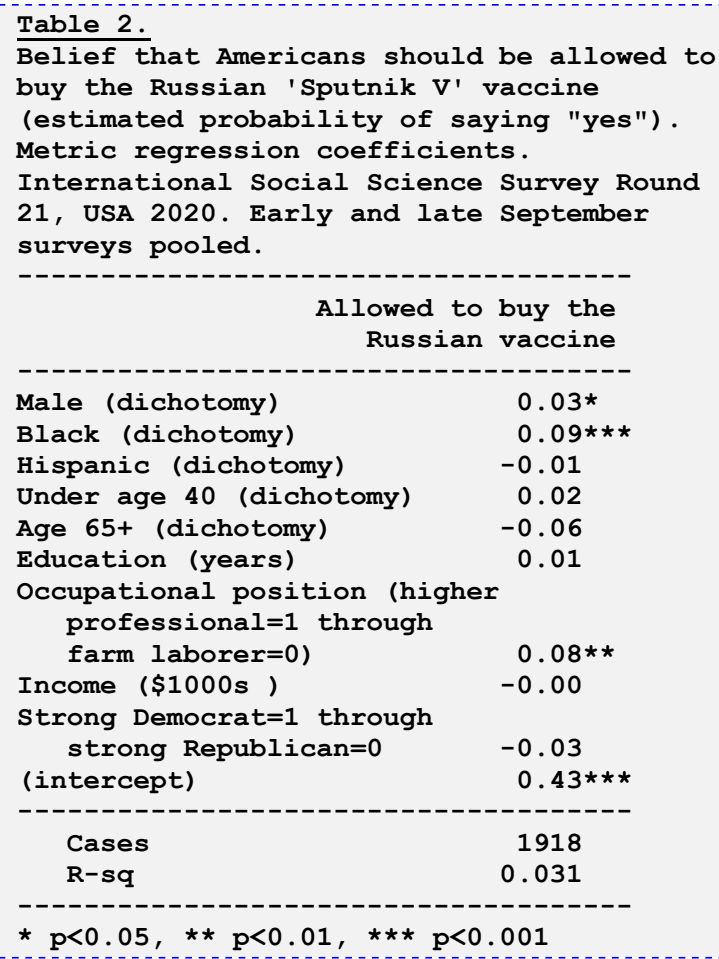

The only real socioeconomic difference that is that those at the top of the occupational hierarchy (professors, lawyers, engineers and other higher professionals) are around $8 \%$ more supportive than those near the bottom of the hierarchy (like unskilled laborers; $\mathrm{t}=2.76, \mathrm{p}<.01$ ). Concretely, $62 \%$ of typical higher professionals believe they should be allowed to buy the 'Sputnik V' vaccine while only $55 \%$ of otherwise similar unskilled workers think that - hardly a big difference. Notice that these are differences only in the size of the majority.

There are no significant partisan differences either $(t=-1.68, p=.09)$. This is unlike many other aspects of the coronavirus epidemic where partisan differences are strong and often heated.

\section{Conclusion}

We have argued that making the Russian coronavirus vaccine 'Sputnik V' immediately available in the US would save approximately 40 to 100 American lives each day after the first month of availability. Many more would be saved subsequently, both from the on-going immunity among the first wave vaccinated, and from subsequent cohorts accepting vaccination. The benefits would continue at least until US vaccines become fully available and fully accepted.

Making the Russian vaccine immediately available for Americans to buy if they want to is a policy supported by a two-to-one majority of the nation. That is a policy supported by rich and poor, young and old, Democrat and Republican alike. Public opinion is no hinderance to adopting it. 
To put the matter bluntly, current US government policy prevents Americans from getting the existing Russian vaccine. This policy will kill some 40 to 100 people each day for a considerable period later this year and early next.

To put that in context, all American murderers combined kill about 45 people each day. That is hardly a record the American government should strive to emulate.

The issue is a moral one: Is it better to be almost absolutely safe for those who eventually take the FDA-approved vaccine at the cost of deaths every day to people who today would have taken Sputnik-V, the vaccine that has not completed the FDA approval process? Does the tiny risk of a bad vaccine reaction causing death justify preventing people from making up their own minds how they weight that tiny risk against the risk they face without taking the vaccine? Or should the scientists stick to the science and provide the best information currently available - and best estimates based on past experience about the relative risks - leaving to the citizenry the right to make up their own minds about how they weigh those risks and to have access to the Russian vaccine if they want it? Our current system is killing about 40 to100 people per day who would have survived had they been allowed to take the vaccine, as they wished. Neither those persons, nor their bereaved families mourning them, would now choose to be deprived of the vaccine. Is our system justified in inflicting these deaths on innocent and unwilling victims?

There is also a practical implication for the 2020 election. Since feelings about the Russian coronavirus vaccine are strongly favorable, and making it immediately available in the US would likely save dozens of lives each day, adopting the policy should be attractive politically. The Republican government has the power to adopt the policy and gain the credit. Alternatively, the Democratic opposition has the opportunity to advocate the policy, and claim the credit.

\section{APPENDIX: THE MODEL}

Our underlying model is described in Sections 4 and 5.1 above.

It is implemented in a straightforward Excel spreadsheet described here. The spreadsheet is freely available for downloading on our website (URL temporarily suppressed for blind review).

Basic assumption: If vaccination reaches $20 \%$ of the population and protects (say) $50 \%$ of those vaccinated from subsequent infection, then it reduces the rate of infection and the death rate - by $10 \%(\operatorname{viz} .20 * .50=.10)$.

The model covers those who intend to get vaccinated "right away", which we take to be in the first month (see Section \#3). These are the results shown in Section \#5, Figure 1.

Those who expect to be vaccinated in the $2^{\text {nd }}$ or subsequent months would follow the same logic and essentially the identical model but starting in the $2^{\text {nd }}$ or subsequent months. These results are briefly discussed in text but not shown numerically. 
The following calculations for those who intend to get vaccinated "right away" are repeated for each week; 9 weeks are shown in Figure 1. The first 4 weeks are the establishment period as the Russian vaccine is taken up, subsequent periods are the stable state.

These calculations are repeated for each week:

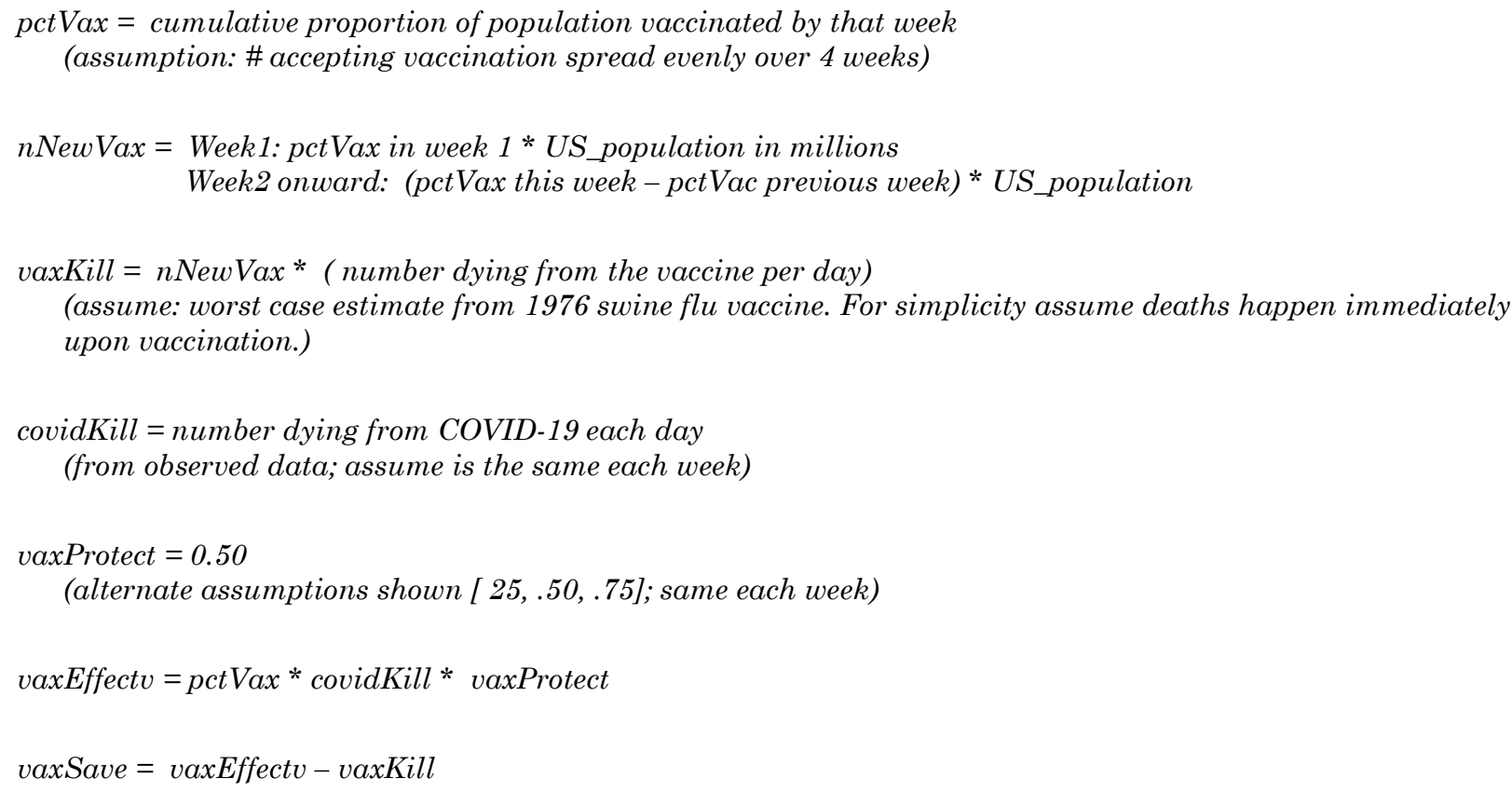

\section{REFERENCES}

Anand, Shuchi, Maria Montez-Rath, Jialin Han, Julie Bozeman, Russell Kerschmann, Paul Beyer, Julie Parsonnet, Glenn M Chertow, et al., 2020. "Prevalence of SARS-CoV-2 antibodies in a large nationwide sample of patients on dialysis in the USA: A cross-sectional study." The Lancet. Published Online September 25, 2020; https://doi.org/10.1016/S0140-6736(20)32009-2

CBS 2020. www.cbsnews.com/news/voters-covid-19-vaccine-opinion-poll

Clifford, Scott, Ryan M Jewell, and Philip D Waggoner. 2015. "Are Samples Drawn from Mechanical Turk Valid for Research on Political Ideology?" Research \& Politics 2(4):doi:10.1177/2053168015622072.

Cornesse, Carina and Annelies G. Blom. 2020. "Response Quality in Nonprobability and Probability-Based Online Panels." Sociological Methods \& Research online first:https://doi.org/10.1177/0049124120914940. doi: https://doi.org/10.1177/0049124120914940.

Evans, M.D.R., and Jonathan Kelley. 2011. "US Attitudes Towards Human Embryonic Stem Cell Research.” Nature Biotechnology 29(6):484-488, plus on-line supplement, pages 1-20.

Graham, Amanda, Francis T. Cullen, Justin T. Pickett, Cheryl Lero Jonson, Murat Haner and Melissa M. Sloan. 2020. "Faith in Trump, Moral Foundations, and Social Distancing Defiance During the Coronavirus Pandemic." Socius 6 (September 10, 2020 ): https://doi.org/10.1177/2378023120956815

Liotta, G., Marazzi, M. C., Orlando, S., \& Palombi, L. 2020. "Is social connectedness a risk factor for the spreading of COVID-19 among older adults? The Italian paradox". Plos One 15(5): e0233329. 
McFadden, S. M., Malik, A. A., Aguolu, O. G., Willebrand, K. S., \& Omer, S. B. 2020. "Perceptions of the adult US population regarding the novel coronavirus outbreak." Plos One 15(4): e0231808.

Millera, Elaine R., Pedro L. Moroa, Maria Canoa, and Tom Shimabukuro. 2015. "Deaths following vaccination: What does the evidence show?" Vaccine; 33(29): 3288-3292. doi:10.1016/j.vaccine.2015.05.023.

Morens, David M. and Anthony S. Fauci. 2020. "Emerging Pandemic Diseases: How We Got to COVID-19." Cell. Published online August 15, 2020. https://doi.org/10.1016/j.cell.2020.08.021

Motta, Matthew. 2020. "Can a COVID-19 Vaccine Live up to Americans' Expectations? A Conjoint Analysis of How Vaccine Characteristics Influence Vaccination Intentions.” SocArXiv. August 27. doi:10.31235/osf.io/kxmw7

Pew, 2020. www.pewresearch.org/science/2020/09/17/u-s-public-now-divided-over-whether-to-get-covid-19-vaccine

Siddiqui, Mariam, Daniel A Salmon, and Saad B Omer. 2013. "Epidemiology of vaccine hesitancy in the United States". Human Vaccines \& Immunotherapeutics 9:12, 2643-2648;

Springer, Victoria A., I. Stephanie Vezich, Samuel C. Lindsey, and Peter J. Martini. 2016. "Practice-Based Considerations for Using Multi-Stage Survey Design to Reach Special Populations on Amazon's Mechanical Turk." Survey Practice 9(5):1-10.

Weinberg, Jill D., Jeremy Freese and David McElhattan. 2014. "Comparing Data Characteristics and Results of an Online Factorial Survey between a Population-Based and a Crowdsource-Recruited Sample." Sociological Science 1(1):292-310. 